\title{
Preparation and characterization of novel bioceramic coatings on Ti6Al4V substrates for biomedical applications
}

\author{
L. Grima ${ }^{1, a^{*}}$, J.I. Peña1, b, J.A. Pardo ${ }^{2, c}$ \\ ${ }^{1}$ Instituto de Ciencia de Materiales de Aragón, Universidad de Zaragoza-CSIC \\ Dpto. Ciencia y Tecnología de Materiales y Fluidos \\ 50.018 Zaragoza, Spain \\ 2Instituto de Nanociencia de Aragón, Universidad de Zaragoza \\ Dpto. Ciencia y Tecnología de Materiales y Fluidos \\ 50.018 Zaragoza, Spain
}

e-mail: a lorenagrimasoriano@gmail.com,bjipena@unizar.es, cjpardo@unizar.es

Key words: Bioceramic coatings, Ti6A14V, Pulsed Laser Deposition.

Abstract. With age bones lose quality being in some cases necessary their replacement. Research is underway on the development of biomaterials to meet the mechanical and biological requirements. One of the most used alloys is Ti6Al4V. The disadvantage of this biomaterial is the formation of a layer of connective tissue between the implant and the surrounding tissue, which makes it difficult to attach to living bone. Ceramic coatings are made on the surface of these metal biomaterials, which improve the communication between the implant and the living tissue.

Ti6Al4V substrates have been coated with a bioactive ceramic with composition 7CaO.P $\mathrm{P}_{2} \mathrm{O}_{5} .2 \mathrm{SiO}_{2}$ by Pulsed laser deposition (PLD). Layers have been deposited under different substrate conditions and their microstructure and composition have been characterized by XRD and SEM.

\section{Introduction}

The increase in the age of the population carries a greater incidence of bone diseases, so that more and more materials are needed to meet the requirements, both mechanical and biological, to which the bone is subjected. Titanium and its alloys exhibit properties such as, biocompatibility, low elastic modulus, high strength-to-weight ratio, excellent corrosion resistance. Ti6Al4V is the titanium alloy which offers the best potential for medical applications due to its excellent balance between their mechanical properties, corrosion resistance, low density, relatively low elastic modulus and excellent biocompatibility [1].

As we well know the effectiveness of orthopedic implants is governed by complete osseointegration between the surface of the material and the bone tissue, without the formation of a fibrous tissue interface. When using titanium as an implant, because it is a bioinert material, this interface can be generated, hindering the correct communication between the prosthesis and the surrounding tissue.

Therefore, numerous techniques are used to cover the titanium implants, reducing the corrosion of the metal and promoting the healing process of the damaged tissue $[2,3,4]$. 
In addition, if we coat titanium implants with bioactive materials we can increase the bioactivity of the metal surface, thus achieving an osteogenic activity in the bone and producing a firm anchorage of the prosthesis to the surrounding bone. For this reason our purpose is generate a coating on a Ti6Al4V substrate of a bioactive ceramic with composition $7 \mathrm{CaO} \cdot \mathrm{P}_{2} \mathrm{O}_{5} .2 \mathrm{SiO}_{2}$, a new single phase $\mathrm{Si}-\mathrm{Ca}-\mathrm{P}$-based ceramic, different from the classical Si-substituted CaP's, like silicocarnotite or $45 \mathrm{~S} 5$ bioglass [5]. The result is a combination of the good mechanical properties of the metal and the bioactive properties of the ceramic, thus obtaining an optimum chemical bond between the implant and the bone. For this purpose, the objectives pursued in this work are the manufacture, characterization and study of the bioactivity of new bioceramics of the $\mathrm{Ca}_{3}\left(\mathrm{PO}_{4}\right)_{2}-\mathrm{Ca}_{2} \mathrm{SiO}_{4}$ binary system. It is considered necessary to prepare it as a crystal and as a coating on substrates of Ti6Al4V as received. For this, several processing techniques based on the use of laser, Laser Floating Zone and Pulsed Laser Deposition, will be used.

\section{Experimental Section}

\section{Study of bioactivity of ceramic material}

Ceramics have been widely used in biomedical applications due to their structural similarity to bone [6]. The main disadvantage they present is its fragility, for this reason in this work is intended the use of a bioceramic as a coating of a metallic material that would be used as structural component of a joint prosthesis. The material used in the present work has the composition $7 \mathrm{CaO} \cdot \mathrm{P}_{2} \mathrm{O}_{5} \cdot 2 \mathrm{SiO}_{2}$ and corresponds to the phase A of Nurse of the phase diagram TCP- $\mathrm{C}_{2} \mathrm{~S}$ [7], being obtained from commercial reactives (A) or from ceramics synthesized in the laboratory (B).

Our material presents another essential feature to be used as part of a joint prosthesis, which is the presence of Silicon. It is believed that Si plays an important role in the processes of bone mineralization around the implant, specifically as an accelerator of these processes $[8,9,10,11]$.

To study its bioactivity starting from the powdered material we have generated crystalline rods by the Laser Floating Zone technique (LFZ). This technique is based on the focusing of a laser beam on a precursor, so a small melt zone is established and it is moving along the sample giving rise to a rod directionally solidified [12]. These solidified rods were cut into slices and placed in Simulated Body Fluid (SBF) during 1,2 and 4 weeks in order to study its bioactivity.

\section{Pulsed Laser Deposition}

After reporting ceramic bioactivity, we must carry out the coat of the metallic material using PLD technique. This technique revolves around focusing a pulsed laser beam on a target, to achieve its ablation. Target material is ejected perpendicular to its surface, forming a plasma. An exploration of conditions has been conducted in order to study the influence of some parameters, such as pressure and temperature, in the coating properties, obtaining a total of seventeen coated samples. 


\section{$\underline{\text { Results }}$}

\section{Bioactivity of the crystal rods.}

As we can see in figure 1, SEM morphological observation of the material submerged in SBF showed a dense structure on which a layer has been formed upon being in contact with SBF. The composition of the layer generated on samples immersed in SFA 1 (A1), 2 $(\mathrm{A} 2, \mathrm{~B} 2)$ and 4 weeks (A4, B4) was determined by EDX analysis and results are shown in Table 1.
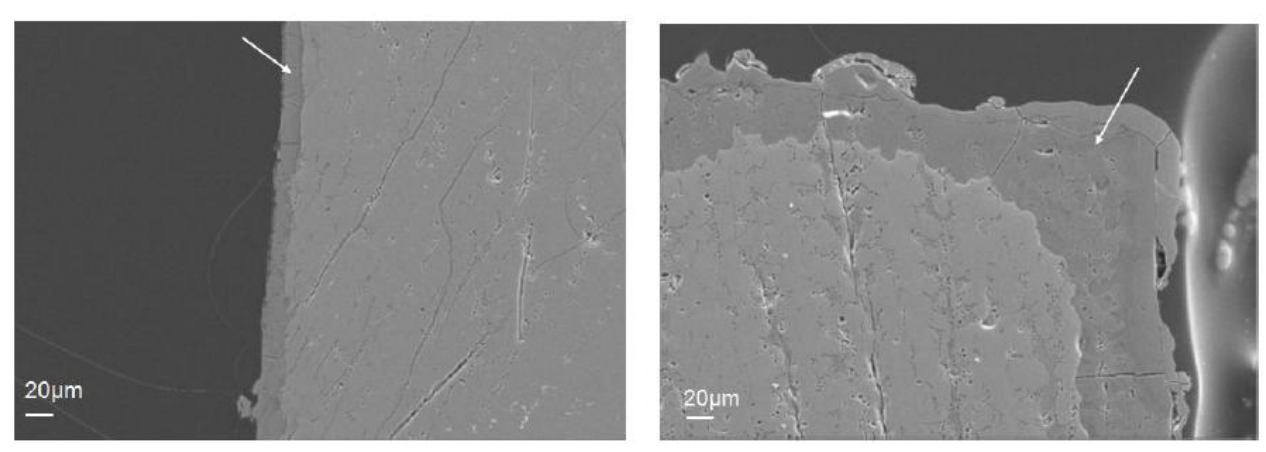

Figure 1. SEM images of samples submerged in SFA for 1 (left) and 4 weeks (right).

\begin{tabular}{cccccc}
\hline & A1 & A2 & A4 & B2 & B4 \\
\hline $\mathbf{C a} / \mathbf{P}$ & $1.47 \pm 0.15$ & $1.58 \pm 0.24$ & $1.59 \pm 0.18$ & $1.68 \pm 0.27$ & $1.66 \pm 0.31$ \\
\hline
\end{tabular}

Table 1. Ca/P ratio in the layer generated on samples immersed in SBF.

It can be seen that the results obtained for the $\mathrm{Ca} / \mathrm{P}$ ratio are very similar to those expected for hydroxyapatite $(1,66)$. This fact proves that our material A and $\mathrm{B}$ is able to generate a layer rich in $\mathrm{Ca}$ and $\mathrm{P}$ when it was in contact with $\mathrm{SBF}$, so it can be said that it is a bioactive ceramic.

\section{Bioceramic coating}

In order to carry out the characterization of samples generated by PLD (thickness, roughness, composition, crystallinity and surface microstructure), techniques such as profilometry, scanning electronic and confocal microscopy and X-ray diffractometry (XRD) have been used.

In figure 2 we can see SEM images of the coating generated after the PLD process. In both images we can observe the formation of a coating, when working at higher temperature than $900^{\circ} \mathrm{C}$ we can appreciate crystalline structures. 

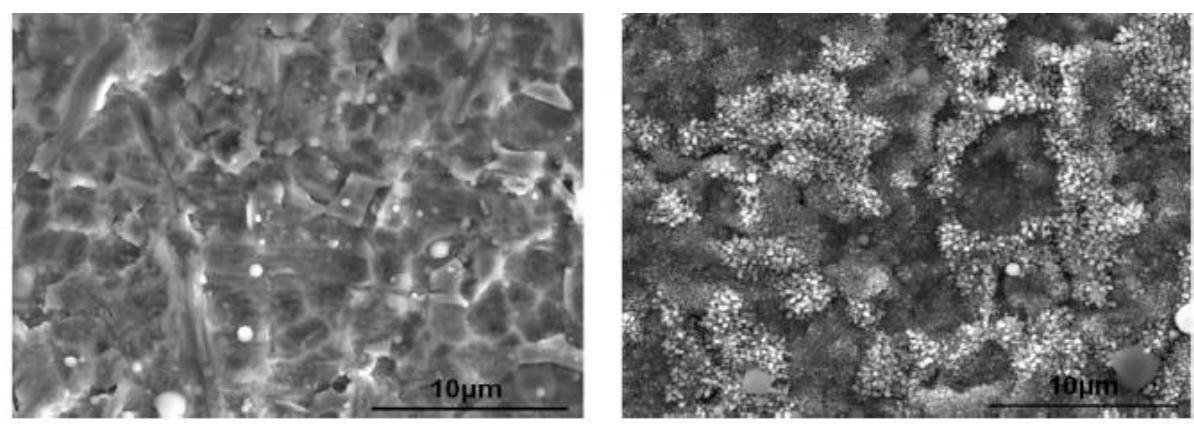

Figure 2. SEM images of the coatings generated by PLD at 700 (left) and $900^{\circ} \mathrm{C}$ (right).

The SEM-EDX microanalysis can determine the composition of the coatings. Knowing that the expected composition is $7 \mathrm{CaO} \cdot \mathrm{P}_{2} \mathrm{O}_{5} .2 \mathrm{SiO}_{2}$ and observing Table 2 it can be observed the processing conditions during the layer deposition, in different samples, and it can be conclude that the composition of the coatings generated is close to the expected results, mainly working at high $\mathrm{T}^{\mathrm{a}}$.

Samples were named following this methodology PLD.ProcessingT -ProcessingP.Target used.

\begin{tabular}{|ccccccc|}
\hline & Ta $\left({ }^{\circ} \mathrm{C}\right.$ ) & PO2 (mTorr) & Blanco & Ca & P & Si \\
\hline 7CaO.P205.2SiO2 & - & - & -- & 7 & 2 & 2 \\
PLD.100.100.A & 100 & 100 & $\mathrm{~A}$ & 6.03 & 2.00 & 2.48 \\
PLD.300.100.A & 300 & 100 & $\mathrm{~A}$ & 5.64 & 2.00 & 2.44 \\
PLD.400.100.A & 400 & 100 & $\mathrm{~A}$ & 5.84 & 2.00 & 2.43 \\
PLD.500.100.A & 500 & 100 & $\mathrm{~A}$ & 5.56 & 2.00 & 2.68 \\
PLD.500.100.A' & 500 & 100 & $\mathrm{~A}$ & 5.34 & 2.00 & 2.28 \\
PLD.600.100.A & 600 & 100 & $\mathrm{~A}$ & 6.78 & 2.00 & 2.99 \\
PLD.700.100.A & 700 & 100 & $\mathrm{~A}$ & 6.62 & 2.00 & 2.69 \\
PLD.800.100.A & 800 & 100 & $\mathrm{~A}$ & 5.83 & 2.00 & 2.34 \\
\hline PLD.900.100.A & 900 & 100 & $\mathrm{~A}$ & 7.07 & 2.00 & 2.32 \\
\hline PLD.850.100.A & 850 & 100 & $\mathrm{~A}$ & 6.50 & 2.00 & 2.30 \\
\hline PLD.950.100.A & 950 & 100 & $\mathrm{~A}$ & 7.02 & 2.00 & 2.16 \\
\hline PLD.400.10.A & 400 & 10 & $\mathrm{~A}$ & 8.25 & 2.00 & 3.16 \\
PLD.500.10.A & 500 & 10 & $\mathrm{~A}$ & 8.89 & 2.00 & 3.20 \\
PLD.600.100.B & 600 & 100 & $\mathrm{~B}$ & 6.43 & 2.00 & 2.97 \\
PLD.500.100.B & 500 & 100 & $\mathrm{~B}$ & 7.34 & 2.00 & 3.23 \\
\hline PLD.950.100.B & 950 & 100 & $\mathrm{~B}$ & 7.89 & 2.00 & 2.95 \\
PLD.900.100.B & 900 & 100 & $\mathrm{~B}$ & 7.69 & 2.00 & 2.92 \\
\hline
\end{tabular}

Table 2. Processing conditions and elemental composition of the coatings generated by PLD.

The thickness of the formed coating was measured with contact profilometry from the step generated by a mask at different points, obtaining values between 1.5 and $2 \mu \mathrm{m}$. The surface roughness of the titanium alloy was measured with confocal microscopy. The results presented in Table 3 indicate that the roughness has not been substantially modified by depositing a ceramic film on the metal. This is important because roughness has an effect on osteoblastic adhesion, proliferation and differentiation $[13,14]$. 


\begin{tabular}{cccc}
\hline & PLD.800.100.A & PLD.950.100.A & Ti6A14V (Substrate) \\
\hline Ra (nm) & 521 & 640 & 569 \\
\hline
\end{tabular}

Table 3. Roughness (Ra) for the uncoated substrate and two coated samples.

When we analyze the samples by DRX, some differences can be observed (Figure 3). Firstly at lower temperature than $800^{\circ} \mathrm{C}$ we can only notice peaks belonging to the metallic substrate. Secondly when we work at greater temperature than $800^{\circ} \mathrm{C}$ we can observe peaks that correspond with the formation of a layer of titanium oxides $\left(\mathrm{TiO}_{2}\right.$ and $\left.\mathrm{Ti}_{2} \mathrm{O}_{3}\right)$, witch can favours the adhesion between the metallic substrate and ceramic layer. Lastly when we work at greater temperature than $900^{\circ} \mathrm{C}$ we can notice that the coating is formed of the Nurse phase while working at lower temperature we can not observe the formation of a crystalline phase in the coating.

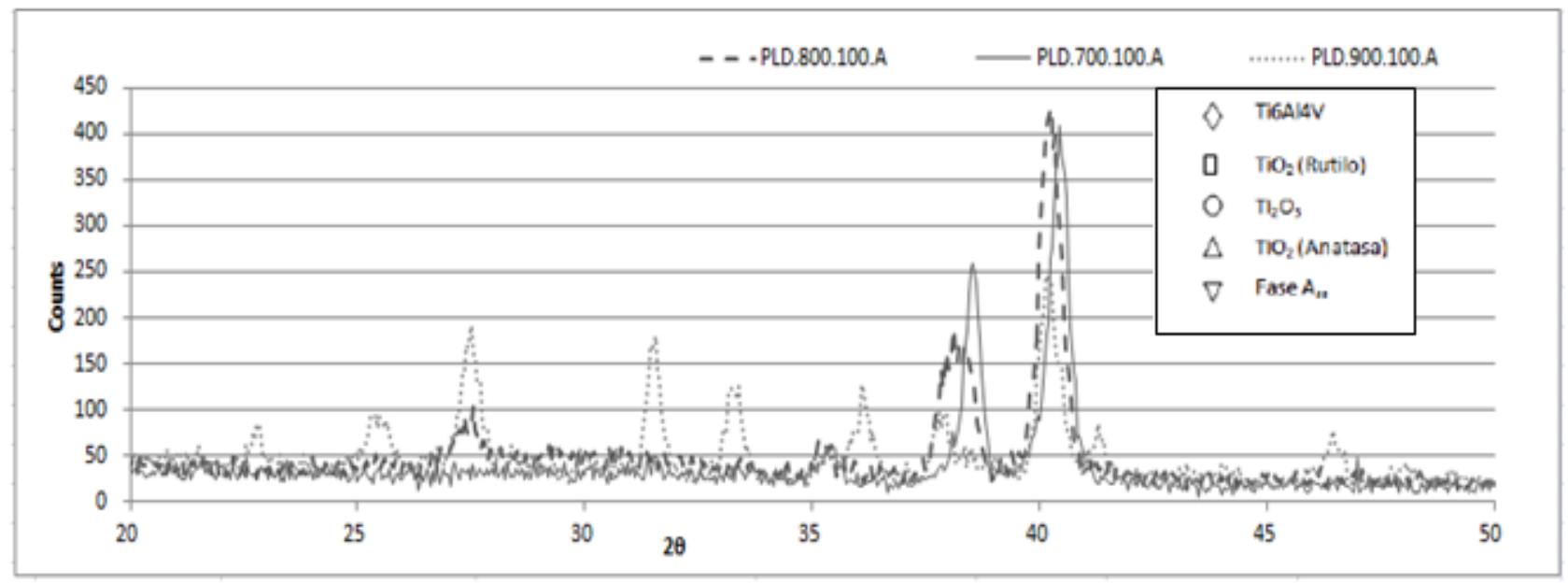

Figure 3. Diffractograms of three samples obtained at different temperatures.

\section{Conclusions}

At the end of this work we can establish the following conclusions:

- Both the bioceramic used to carry out the coating and the material obtained by directional solidified with composition $7 \mathrm{CaO} \cdot \mathrm{P}_{2} \mathrm{O}_{5} .2 \mathrm{SiO}_{2}$ has a bioactive character. This fact would favour the attachment of the surface of the implant to the bone.

- Bioceramic coatings on substrates of the Ti6Al4V alloy have been deposited by PLD. By means of the precise control of the process parameters, the composition of the target (7CaO.P $\mathrm{O}_{5} .2 \mathrm{SiO}_{2}$ ) has been transferred stoichiometrically, as well as choosing between the amorphous (at temperatures lower than $900^{\circ} \mathrm{C}$ ) or crystalline structure of these coatings (at temperatures of 900 and $950^{\circ} \mathrm{C}$ ).

- When we work at $800^{\circ} \mathrm{C}$ or higher temperatures we detected the formation of crystalline phases (rutile and anatase $\mathrm{TiO}_{2}$, and even $\mathrm{Ti}_{2} \mathrm{O}_{3}$ ). This is due because of the metallic substrate was in an oxygen atmosphere, during the PLD process, so a layer of titanium oxide is generated on the surface of the substrate (Ti6Al4V), this fact may 
decrease the $\mathrm{Ti}$ and $\mathrm{Al}$ release from the Ti64 and improve the osteoblastic adhesion [15].

It was concluded that the metal-bioceramic assembly would be useful in its use as an implant material in arthroplasties, due to the substrate (Ti6Al4V) would serve as a mechanical support and the coating would improve the adhesion of bone cells, as well as the osseointegration of the same in the guest.

\section{Acknowledgments}

Authors thanks to Piedad de Aza and Pablo Velasquez of the Universidad Miguel Hernández, Elche, for the preparation of the ceramic precursors and for their helps in the results discussion.

\section{References}

[1] Mitsuo Niinomi. Mechanical properties of biomedical titanium alloys. Materials Science and Engineering, A243, pp 231-236, (1998).

[2]R. Drevet, N. Ben Jaber, J. Fauré, A. Tara, A. Ben Cheikh Larbi, H. Benhayoune. Electrophoretic deposition (EPD) of nano-hydroxyapatite coatings with improved mechanical properties on prosthetic Ti6Al4V substrates. Surface \& Coatings Technology 301 (2016) 94-99.

[3]G. Miranda, A. Araújo , F. Bartolomeu , M. Buciumeanu, O. Carvalho, J.C.M. Souza, F.S. Silva, B. Henriques. Design of Ti6Al4V-HA composites produced by hot pressing for biomedical applications. Materials and Design. Vol 108, pp 488-493, (2016).

[4]Yaser E. Greish, Ahmed S. Al Shamsi, Kyriaki Polychronopoulou, Ahmad I. Ayesh. Structural evaluation, preliminary in vitro stability and electrochemical behavior of apatite coatings on Ti6Al4V substrates. Ceramics International, Vol 42, pp 18204-18214, (2016).

[5]. Gerardo J. Lugo, Patricia Mazón, Carmen Baudin, and Piedad N. De Aza. Nurse's APhase: Synthesis and Characterization in the Binary System Ca2SiO4-Ca3(PO4)2. J. Am. Ceram. Soc., 98 [10] 3042-3046 (2015).

[6] Alejandro Sáenz, Eric Rivera-Muñoz, Witold Brostow and Victor M. Castaño. Ceramic biomaterials: an introductory overview. Journal of Materials Education, Vol.21 (5-6), pp 297 - 306, (1999).

[7] W. Fix, H. Heymann, and R. Heinke. Subsolidus Relations in System 2CaO. $\mathrm{SiO}_{2-}$ 3CaO.P $\mathrm{P}_{2} \mathrm{O}_{5}$. Journal of the American Society. Vol. 52, 1969.

[8]. Felix Bronner. "Metals in Bone: aluminum, boron, cadmium, chromium, lead, silicon, and strontium". Principles of bone biology. Academic Press, Inc. (1996).

[9]. Hench LL, Xynos ID, Polak JM. Bioactive glasses for in situ tissue regeneration. Journal of Biomaterials Science Polymer Edition, Vol 15(4), pp 543-62, (2004).

[10]. R. Jugdaohsingh. Silicon and bone health. J Nutr Health Aging. Vol 11(2), pp 99-110, (2007).

[11]. Porter AE, Patel N, Skepper JN, Best SM, Bonfield W. Effect of sintered silicatesubstituted hydroxyapatite on remodelling processes at the bone-implant interface. Biomaterials. Vol 25, pp 3303-3314, (2004). 
[12] Piedad N. De Aza, Jose I. Peña, Zofia B. Luklinska and Luis Meseguer-Olmo. Bioeutectic ${ }^{\circledR}$ Ceramics for Biomedical Application Obtained by Laser Floating Zone Method. In vivo Evaluation. Materials 2014, 7(4), 2395-2410.

[13]. Anselme K. Osteoblast adhesión on biomaterials, Biomaterials, Vol. 21, pp 667-681, (2000).

[14]. Boyan BD, Lohmann CH, Dean DD, Sylvia VL, Cochran DL, Dean DD, Schwartz Z. Both cyclooxygenase-1 and cyclooxigenase-2 mediate osteoblast response to titanium surface roughness. J Biomed. Mater. Res. Vol. 55, pp 350-359, (2001).

[15]. M.C. García-Alonso, L. Saldaña, G. Vallés, J.L. González-Carrasco, J. GonzálezCabrero, M.E. Martínez, E. Gil-Garay, L. Munuera. In vitro corrosion behaviour and osteoblast response of thermally oxidised Ti6Al4V alloy. Biomaterials, Vol 24, pp 19-26, (2003). 